\title{
On the pathogenesis of the irritable bowel syndrome: The irritable bowel or the irritable patient?
}

\author{
STEPHEN M COLLINS, MBBS, FRCP(UK), FRCPC
}

\begin{abstract}
The traditional perspective of irritable bowel syndrome (IBS) as a behavioural problem has tended to downplay the role of gastrointestinal dysfunction. Contrary to predictions based on the traditional philosophy, a recent study has shown that IBS patients have increased pain tolerance compared to healthy subjects. This profile of pain tolerance is similar to that seen in chronic organic disease of the gut (eg, Crohn's disease), raising the possibility that IBS patients may experience pain resulting from gastrointestinal dysfunction. The recent finding of increased airway responsiveness to inhaled methacholine in certain IBS patients provides an objective and quantifiable measurement of tissue dysfunction in that syndrome, and focuses attention on possible mechanisms underlying the altered responsiveness of hollow organs in patients with IBS; these mechanisms are discussed. Can J Gastroenterol 1990;4(1):33-38
\end{abstract}

Key Words: Asthma, Behaviour, Inflammation, Motility, Smooth muscle, Stress

The Intestinal Diseases Research Unit, McMaster University, Hamilton, Ontario

Correspondence and reprints: Dr S.M. Collins, Associate Professor of Medicine, Director, The Intestinal Diseases Research Unit, Room 3N5c-HSC, McMaster University Medical Centre, Hamilton, Ontario L8N 325. Telephone (416) 525-9140 ext 2585

Received for publication August 4, 1989. Accepted September 19, 1989
T HE ISSUE OF WHETHER THE IRRITABLE bowel syndrome (IBS) reflects a primary disorder of the brain or the gut has plagued gastroenterologists, psychologists and psychiatrists for years. An editorial published in The Lancet in 1984 crystallized the controversy by stating: "At one end of the spectrum is the belief that the primary disorder is almost entirely psychiatric: the patients are anxious, dependent, hysterical or otherwise deranged, and their symptoms are largely imaginary, or at the very least grossly exaggerated...At the other end of the scale is the notion that the irritable bowel syndrome is an organic disorder of gut function" (1). The controversy hinges on the idea that IBS must be an exclusive disorder of the brain or gut, and the no- 


\section{La pathogenèse du syndrome du côlon irritable : Côlon ou pa- tient irritable?}

RESUME: A cause de la perspective traditionnelle qui consiste à voir le syndrome du côlon irritable (IBS-SGI) comme un problème de comportement avant tout, on a eu tendance à accorder une importance moindre à la compréhension des causes du dysfonctionnement gastrointestinal dans cette affection. Or, contrairement aux prévisions conformes à cette philosophie, une étude récente démontre que les patients souffrant de SGI manifestent une tolérance accrue à la douleur, comparés aux sujets en bonne santé. Ce profil de tolérance à la douleur est semblable à celui que l'on observe dans le cas d'autres maladies organiques chroniques de l'intestin (maladie de Crohn, par exemple); il serait donc possible que les patients atteints de SGI souffrent bien de douleurs résultant d'une dysfonction gastrointestinale. Des résultats récents montrent, chez certains de ces patients, une faculté de réponse accrue des voies aériennes aux inhalations de méthacholine fournissant une mesure objective et quantifiable de la dysfonction des tissus dans ce syndrome et attirant l'attention sur les mécanismes qui sont peut-être à l'oeuvre dans la faculté de réponse altérée des organes creux chez ces patients; ces mécanismes sont examinés.

tion that IBS represents a single pathogenetic process. Since it is unlikely that either of these views is correct, one may claim that the controversy is, to some extent, artificial.

\section{IRRITABLE MIND?}

The traditional and hitherto dominant view of IBS has been that it represents a primary behavioural problem, and that if indeed there is any gastrointestinal dysfunction, the gut is involved as an "innocent bystander'. This view is supported by both scientific data and sentiment.

The main body of evidence in support of a primary behavioural basis for IBS comes from studies that demonstrate an abnormal behavioural profile in the IBS patient population, and from studies reporting improvement in IBS symptoms following psychotherapy or the use of psychotropic drugs (Table 1). As a group, IBS patients generally appear to be psychologically fragile; this is borne out in formal psychometric assessments. There is a higher than expected prevalence of

\section{TABLE 1}

\section{Factors in favour of a primary behavioural} cause of IBS

\section{Abnormal personality profiles}

Higher incidence of affective disorders

Precipitation of symptoms by stress

Responses to psychotropic drugs

Responses to psychotherapy and hypnosis

Limited demonstrable efficacy of

gastrointestinal drugs depression, anxiety and other neuroses (2-5). However, it should be remembered that these studies were performed largely on patients in tertiary referral centres which attract the more chronic and refractory patients. Perhaps it is not surprising that this group should exhibit signs of anxiety or depression; little is known of the psychometric profile of IBS patients early in the course of their illness.

There is evidence from controlled trials that antidepressants (6-10), psychotherapy (11) and hypnotherapy (12) may improve gastrointestinal symptoms in certain IBS patients, but the applicability of these treatment strategies to the IBS patient population as a whole is questionable. In clinical practice, one is conscious of the overtly anxious or depressed IBS patient in whom such measures are appropriate, but there are also many IBS patients with severe symptoms who are psychologically robust and in whom these therapeutic strategies are likely to be ineffective and perhaps offensive. These observations underscore the suspicion that the clinical entity 'IBS' may be the expression of several quite dissimilar pathogenetic processes, some of which impact directly on the gut and others which do so via the central nervous system.

The paucity of nonpsychotropic therapies of proven efficacy for the gastrointestinal symptoms in IBS may be misconstrued as evidence in favour of a primarily behavioural etiology. However, there exist several other reasons why a drug might exhibit poorly demonstrable efficacy against these symptoms (Table 2). The first and most obvious reason is that traditional methods for evaluating drug efficacy are inappropriate for a condition that is heterogeneous not only in its clinical presentation, but most likely in its pathogenesis. Methods for evaluating drug efficacy require patient homogeneity, a relatively low placebo effect and a predictable and stable course of the disease over time. They do not take into account the considerable heterogeneity of the patient population, the very high placebo rate, or the spontaneous relapses and remissions that characterize IBS. This subject has recently been reviewed in depth (13).

\section{TABLE 2}

Reasons for limited proven efficacy of gastrointestinal drugs in IBS

Inappropriate study design

Incomplete understanding of basis for gastrointestinal symptoms

Limited understanding of drug action and the pharmacology of gut motility

Actual absence of efficacy

Another reason for the failure to demonstrate drug efficacy against gastrointestinal symptoms in IBS is the limited understanding of the mechanisms underlying these symptoms. Although there are considerable data illustrating motility disturbances throughout the gut in IBS patients, the relationship between symptoms and abnormal motor patterns is incompletely understood. This is perhaps most pronounced in relation to ab. dominal pain; it is likely better understood in the case of constipation and diarrhea. A further problem rests with the complexities of the pharmacology of gastrointestinal motility (14). These issues are serious ones in that they may not only mislead one into believing that potentially useful drugs have no place in the treatment of IBS, but may also prompt one to dismiss the notion that gastrointestinal dysfunction exists as a basis for symptoms in IBS

A different argument that mitigates in favour of a primary behavioural abnormality in IBS is the demonstration that symptoms similar to those reported 


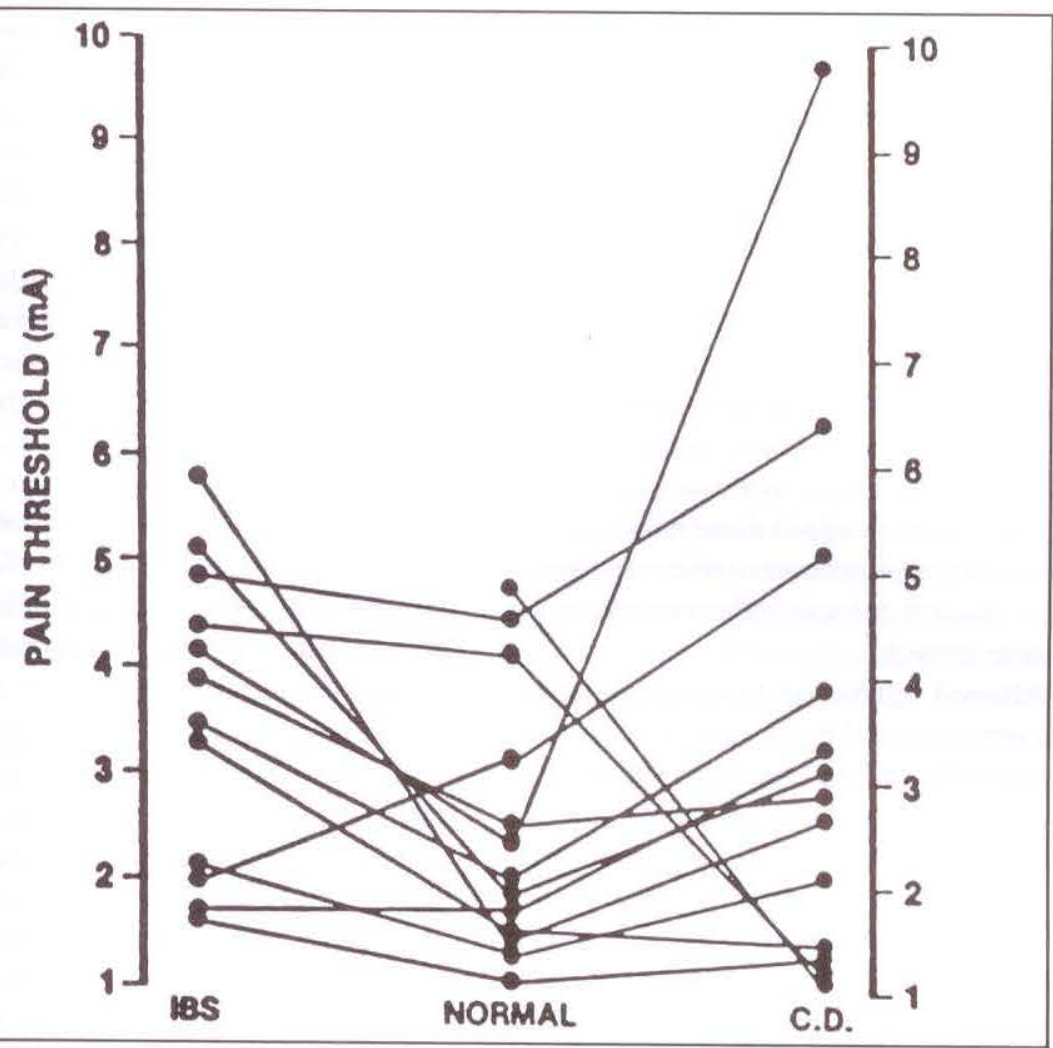

Figure 1) Pain thresholds to electrocutaneous stimuli for patients with IBS or Crohn's disease and matched controls. Pain threshold is the current at which the subject first describes the stimulus as painful. The connecting lines represent individual differences between patients and matched controls. Threshvids for IBS and Crohn's disease patients were significantly higher than matched controls. (Reproduced with permission from Cook et al 1987;93:727-33 Gastroenterology)

in IBS are experienced, but not reported, by as much as $14 \%$ of the population $(15,16)$. This finding, taken in conjunction with a report of a greater prevalence of learned illness behaviour in IBS patients compared to those with peptic ulcer disease (17), suggests that IBS patients are intolerant of 'normal' gastrointestinal sensations and use this experience to seek attention.

Since pain is the symptom that has been shown to be the most common reason for IBS patients to seek attention, one might surmise that such patients select themselves from the general population by virtue of poor pain tolerance. If one assumes, for a moment, that gut function is normal in IBS, then previous reports of intolerance to balloon distension of the rectum in IBS patients support this notion (18). However, the results of a recent study seriously weaken this argument.

Pain perception and reporting were examined in IBS patients using electrocutaneous stimulation over the dorsum of the hand (Figure 1)(19). Results were compared to those obtained in healthy controls and in a group of patients with chronic abdominal pain due to Crohn's disease. Both IBS and Crohn's disease patients had significantly $(\mathrm{P}=0.016)$ higher pain thresholds than normals, and these thresholds were similar in the IBS and Crohn's disease groups. In addition, touch thresholds were higher in these groups compared to the controls, and were significantly higher in the IBS patients than in those with Crohn's disease. These results indicate that IBS patients are less sensitive to low intensity nonpainful stimuli (touch) and have a higher threshold for painful stimuli than normal subjects. The results suggest that IBS patients do not select themselves from the general population by virtue of a generalized reduction in pain tolerance. It follows that reports of pain by IBS patients should not be disregarded as a manifestation of learned illness behaviour.

Since the ability to tolerate higher lev- els of pain is usually associated with painful chronic conditions (20-22) and can be induced in animals subjected to pain (23), the results suggest that IBS patients experience chronic pain on the basis of gastrointestinal dysfunction.

\section{IRRITABLE BOWEL?}

There is an emerging literature which demonstrates that sensory perception within the gut is altered in IBS patients, suggesting that the bowel may be truly 'irritable'. Although the emphasis has been placed on an altered motor function in IBS, it is likely that the exaggerated motor responses observed in IBS may reflect, at least in part, altered sensory input.

Earlier studies reporting intolerance to balloon distension of the rectum in IBS patients (17) support the notion that there is altered sensory input from the gut, particularly if one accepts that these patients are able to tolerate larger amounts of pain than normal subjects (19). The demonstration of abnormal vagal activity in IBS patients (24) may also reflect this, particularly as the majority of the vagal fibres are afferent. Recently reported studies provide further evidence of 'irritability' in the gastrointestinal tract of IBS patients.

One study extended previous work by showing that intolerance to balloon distension is evident in the stomach of patients with idiopathic functional dyspepsia, which may represent a subgroup of the IBS population (25). Another study examined the ability of various luminal stimuli to induce pain and/or colonic motor responses in IBS patients and controls. The luminal stimuli consisted of balloon distension, infusion of $15 \mathrm{mM}$ deoxycholic acid (DCA) and of a mixture of short chain fatty acids (SCFA) $(70 \mathrm{mM}$ acetic acid and $50 \mathrm{mM}$ lactic acid) delivered in random order and interspersed with saline infusion (26). DCA infusion reproduced the familiar pain in seven of eight IBS patients but in only one of five controls. SCFA infusion produced similar responses in five of seven IBS patients but in none of the five controls. The threshold for pain induced by balloon distension of the distal colon was lower in IBS patients compared to the control threshold $(75.7$ versus $171 \mathrm{~mL}$. 
$\mathrm{P}<0.001$ ). Although the motor responses to the acid infusions were larger in IBS patients compared to the controls, the differences were not significant. These results suggest that there is an increased sensitivity of afferent nerves responding to mechanical or chemical stimulation in the gut of IBS patients, which contrasts sharply with the demonstration of increased pain thresholds outside the gut in IBS patients. The implication is that the gastrointestinal tract is indeed abnormal in IBS patients.

\section{GASTROINTESTINAL DYSFUNCTION IN IBS}

Altered motor function: Previous discussions regarding the nature of gastrointestinal dysfunction in IBS have tended to focus on motor abnormalities, and there has even been speculation on the existence of a primary disorder of smooth muscle in the gut in IBS (27). This was prompted in part by demonstrations of altered myoelectric activity recorded in vivo from the unstimulated colon of IBS patients, and in particular the suggestion that there may be an altered slow wave frequency with a higher incidence of 3 cycles/min activity in IBS (28-30). Since slow waves are generated by oscillations in membrane potential, changes in slow wave frequency may be regarded as manifestations of a fundamental alteration in smooth muscle cell (31). However, this finding has not proven to be robust and several other workers have failed to demonstrate it (32-33).

This has as much to do with the difficulties in obtaining and processing electrical signals from the human colon (34) as it does with the inherent complexity and variability of the electrophysiologic control of colonic motility (35). The question of whether there is a primary abnormality in smooth muscle cell function in IBS remains open, but it is this author's opinion that if such an abnormality exists, it does so only in a subpopulation of patients; as already mentioned, IBS is likely to reflect more than one pathogenetic process.

In spite of the uncertainty regarding a primary role for smooth muscle dysfunction in IBS, there is little doubt that stimulated motor activity is abnormal in IBS. Several studies have shown that motor responses to nutrients $(36,37)$, to drugs (38), to hormones (39) and to bile acids $(40)$ are exaggerated in IBS patients versus controls. Since some of these stimuli were delivered via the gut lumen, the exaggerated motor response may reflect, in part, an altered sensory input. However, in certain instances, stimuli such as cholecystokinin and parasympathomimetic drugs were delivered parenterally and would be presumed to act on the motor apparatus directly. The extent to which these responses reflect changes in enteric (efferent) nerves or smooth muscle cells remains to be determined.

Altered epithelial function: Altered gastrointestinal function in IBS is not restricted to the neuromuscular tissues. A study from Denmark has shown that the intestinal epithelium from patients with diarrhea-predominant IBS exhibits net secretory characteristics compared to controls when challenged with bile acids (41). In addition, there is a study in which patients with IBS and a specific food intolerance produced more prostaglandin $\mathrm{E}_{2}$ in the gut lumen when challenged in a double blind manner (42). Although the source of the prostaglandins could not be identified, it was most likely produced by the epithelium and is unlikely to have originated in the deep muscular layers of the gut wall.

\section{IRRITABLE BODY?}

The prevalence of extragastrointestinal symptoms in IBS patients $(43,44)$ has prompted the investigation of dysfunction in hollow organs outside the gut in IBS patients. Abnormal urodynamics have been recorded in patients with constipation due to colonic inertia (45) and in other IBS patients (46). Others have reported significantly lower blood pressures in a group of IBS patients compared to controls (47-49). Some of these data have been interpreted as providing evidence of altered smooth muscle function $(46,47,49)$. However, vascular and urinary bladder responses may reflect hormonal and neural as well as muscular factors, and data obtained from such studies are difficult to quantitate accurately.

To pursue this issue further, and to overcome some of the obstacles found in previous studies, airway responsiveness was recently examined in IBS patients. In humans, the measurement of the volume of air expired in $1 \mathrm{~s}$ under maximal effort following methacholine or histamine inhalation $\left(\mathrm{FEV}_{1}\right)$ is a reliable method of assessing bronchial airway calibre and reactivity $(50-52)$. The response to inhaled methacholine isgenerally considered to reflect an interace tion with muscarinic receptors on airway smooth muscle (53). IBS patients were found to be significantly more sensitive to the bronchoconstricting effects of methacholine than a group of healthy subjects or those with organic diseases of the gastrointestinal tract (54). Significantly larger changes in FEV, were recorded in IBS patients and occurred following the administration of signifcantly smaller amounts of methacholine than was required in other groups. The changes in $\mathrm{FEV}_{\text {, were not, however, of }}$ the magnitude observed in asthmatic patients, and none of the IBS patients studied were atopic.

What are the implications of these results? First, they provide bona fide evidence of altered smooth muscle function outside the gut in IBS patients. The alteration in smooth muscle function may be primary secondary to altered innervation of the muscle or, as in asthma, the consequence of an inflammatory process in the airways. Second, these results raise the spectre of a convenient screening test for IBS patients, although it must be emphasized that the results were obtained in a highly selected IBS group and it is not known whether the findings can be extrapolated to the IBS population at large. Finally, the results prompt comparisons between IBS and asthma.

\section{IBS AS 'THE ASTHMA OF THE GUT'}

Could IBS, or subgroups of IBS, patients reflect the same spectrum of pathophysiological processes that are believed to produce asthma? Why not? There are broad similarities between the digestive and respiratory tracts, and several strik. ing similarities between the two conditions (Table 3).

Let us recall that asthma was considered initially to be a largely psychogenic 
TABLE 3

Similarities between asthma and IBS

\begin{tabular}{llrlr}
\hline & \multicolumn{3}{l}{ Asthma } & \multicolumn{1}{l}{ IBS } \\
\hline Altered smooth muscle function & Yes & $(53)$ & Yes & $(28-30)$ \\
Hyperresponsiveness on pharmacologic stimulation & Yes & $(51)$ & Yes & $(38.39)$ \\
Triggered or exacerbated by local infection & Yes & $(53,58)$ & Yes & $(59)$ \\
Psychological factors implicated in the pathogenesis & Yes & $(55-7)$ & Yes & $(1)$ \\
Mast cells implicated & Yes $(60)$ & Yes & $(61)$ \\
Inflammation implicated & Yes & $(53,58)$ & Yes & $(42,49)$
\end{tabular}

"Primarily in chilidhood asthma. but originally in all asthma. " In the context of post-infectious IBS (49) and the demonstration of increased prostaglandin production in IBS patients with specific food intolerance

disorder in which pulmonary function, but not structure, was altered (55-57), much along the same lines as IBS is now traditionally considered $(3,4,5,17)$. How-

\section{REFERENCES}

1. An irritable mind or an irritable bowel? Lancet 1984;vol ii: 1249-50. (Edit)

2. Hislop IG. Psychological significance of the irritable bowel syndrome. Gut 1971:12:452-7.

3. Palmer RL, Stonehill E, Crisp AH, Waller SL, Misiewicz JJ. Psychological characteristics of patients with the irritable bowel syndrome. Postgrad Med J 1974:50:416-9.

4. Young SJ, Alpers DH, Norland CC, Woojtruff RA. Psychiatric illness and the irritable bowel syndrome. Gastroenterology 1976;70: 162-6.

5. Esler MD, Goulston KJ. Levels of anxiety in colonic disorders. N Engl J Med 1973;288:16-20.

6. Steinhart MJ, Wong H, Zarr ML. Therapeutic usefulness of amitryptyline in spastic colon syndrome. Int J Psychiatry Med 1982;11:45-57.

7. Lancaster-Smith MJ. Prout BJ, Pinto T. Influence of drug treatment in the irritable bowel syndrome and its interaction with psychoneurotic morbidity. Acta Psychiatr Scand 1982; 66:33-41.

8. Myren J, Lovland B, Larssen SE, Larsen S. A double blind study of the effect of trimipramine in patients with the irritable bowel syndrome. Scand ] Gastroenterol 1982;18:871-5.

9. Greenbaum DS, Mayle JE, Vanegeren LE, et al. Effects of desipramine on irritable bowel syndrome compared with atropine and placebo. Dig Dis Sci 1987;32:257-66

10. Dotevall G, Groll E. Controlled clinical trial of mepiprazole in irritable bowel syndrome. Br Med J 1974;2:16-8.

11. Svedlund J, Sjodin I, Ottosson J-O, Dotevall G. Controlled trial of psychotherapy in the irritable bowel syndrome. Lancet 1983;ii:589-92.

12. Whorwell P], Prior A, Faragher EB. Controlled trial of hypnotherapy in the ever, the perception of asthma changed considerably as research uncovered the mechanisms underlying the increased responsiveness of bronchial smooth mus-

treatment of severe refractory irritable bowel syndrome. Lancet 1984;i:1232-4.

13. Klein KB. Controlled treatment trials in the irritable bowel syndrome. Gastroenterology 1988;95:232-41.

14. Daniel EE, Collins SM. Fox JET, Huizinga J. The pharmacology of drugs acting on gastrointestinal motility. In: Wood JE, ed. Handbook of Physiology. Boca Raton: CRC Press. (In press)

15. Thompson WG, Heaton KW. Functional bowel disorders in apparently healthy people. Gastroenterology 1980;79:283-8.

16. Drossman DA, Sandler RS, McKee DC, Lovitz AJ. Bowel dysfunction among subjects not seeking health care. Gastroenterology 1982;83:529-34.

17. Whitehead WE, Winger C, Fedoravicius AS, Wooley S, Blackwell B. Learned illness behaviour in patients with irritable bowel syndrome and peptic ulcer. Dig Dis Sci 1982:27:202-8.

18. Ritchie J. Pain from distension of the pelvic colon by inflating a balloon in the irritable colon syndrome, Gut 1973; 14:125-32.

19. Cook IJ, van Eeden A, Collins SM Patients with irritable bowel syndrome have greater pain tolerance than normal subjects. Gastroenterology 1987: 93:727-33

20. Hazouri LA, Mueller AD. Pain threshold studies on paraplegic patients. Arch Neurol Psychiatry 1950;64:607-13.

21. Cohen MJ, Naliboff BD, Schandler SL, Heinrich RL. Signal detection and threshold measures to loud tones and radiant heat in chronic low back pain patients and cohort controls. Pain 1983;16:245-52.

22. Nathan PW. Improvement in cutaneous sensibility associated with relief of pain. J Neurol Neurosurg Psychiatry 1960;23:202-6.

23. Madden J, Akil H, Patrick RL, Barchas JD. Stress-induced parallel changes in cle (53). An understanding of these mechanisms has in turn led to a more rational and efficacious pharmacotherapy for asthma. The lesson to be learned is that one must persist in investigating this common and often frustrating clinical problem. To dismiss it as a psychogenic disorder is to overlook an increasing body of evidence which points to altered function in tissues inside and outside the gut. We must continue to investigate the mechanisms whereby the gut becomes 'irritable' or 'hyperresponsive', bearing in mind that these mechanisms may have their origins in the brain, the gut and the environment.

central opioid levels and pain responsiveness in the rat. Nature 1977;265:358-60.

24. Smart HL, Atkinson M. Abnormal vagal function in irritable bowel syndrome. Lancet 1987;i:475-8.

25. Lemann M, Dederding JP, Jian R, Flourie B, Franchisseur C, Rambaud JC. Abnormal sensory perception to gastric distension in patients with chronic idiopathic dyspepsia - The irritable stomach. Gastroenterology 1989; 96:A294.

26. Tack J, Coremans G, Vantrappen G, Janssens J, Annese V. Is the irritable colon really irritable? Gastroenterology 1989;69:A499

27. Drossman DA, Powell DW Sessions JT The irritable bowel syndrome. Gastroenterology 1977;73:811-22.

28. Snape WJ, Carlson GM, Cohen S. Colonic myoelectrical activity in the irritable bowel syndrome. Gastroenterology 1976;70:326-30.

29. Taylor IA, Darby C, Hammond P. Comparison of rectosigmoid myoelectrical activity in irritable colon syndrome during relapses and remissions. Gut 1978; 19:923-9.

30. Frieri BG, Parisi F, Corazziari E, Caprilli R. Colonic electromyography in chronic constipation. Gastroenterology 1983; 84:737-40.

31. Huizinga JD, Stern HS, Chow E, Diamant N, El-Sharkawy TY. Electrophysiologic control of motility in the human colon. Gastroenterology 1985; 88:500-11.

32. Latimer P, Sarna S, Campbell D, Latimer M, Waterfall W, Daniel EE Colonic motor and myoelectrical activity: A comparative study of normal subjects, psychoneurotic patients and patients with irritable bowel syndrome. Gastroenterology 1981;80:893-901.

33. Bueno L, Fioramonti ], Ruckebusch Y, Frexinous J, Coulom P. Evaluation of 
colonic myoelectrical activity in health and functional disorders. Gut 1980;21:480-5.

34. Reddy RN, Collins SM, Daniel EE. Frequency analysis of colonic EMG: An applied review. Critical Rev Biomed Eng 1987;15:95-116.

35. Huizinga JD, Daniel EE. Control of human colonic motor function. Dig Dis Sci 1986;31:865-77.

36. Waller S, Misiewicz JJ, Kiley N. Effect of eating on motility of the pelvic colon in constipation and in diarrhoea. Gut 1972;13:805-11

37. Sullivan MA, Cohen S, Snape WJ. Colonic myoelectrical activity in irritable bowel syndrome. Effect of eating and anticholinergics. N Engl J Med 1978;298:878-83.

38. Chaudhary NA, Truelove SC. Human colonic motility: A comparative study of normal subjects, patients with ulcerative colitis and patients with the irritable colon syndrome. II. The effect of prostigmin. Gastroenterology 1961; 40:18-26

39. Harvey RF, Read AE. Effect of cholecystokinin on colonic motility and symptoms in patients with irritable bowel syndrome. Lancet 1973;1:1-3.

40. Taylor I, Basu P. Hammond P, Darby C, Flynn M. Effect of bile acid perfusion on colonic motor function in patients with irritablescolon syndrome. Gut 1980; 21:843-7.

41. Oddsson E, Rask-Madsen J, Drag E. A secretory epithelium of the small intestine with increased sensitivity to bile acids in irritable bowel syndrome associated with diarrhea. Scand J
Gastroenterol 1978;13:409-16.

42. Jones VA, McLaughlan P, Shorthouse M, Workman E, Hunter WO. Food intolerance: A major factor in the pathogenesis of irritable bowel syndrome. Lancet 1982;ii:1115-7.

43. Kirsner JB, Palmer WL. The irritable colon. Gastroenterology 1958;34:941-501.

44. Fielding JF. A year in the outpatients with the irritable bowel syndrome. Ir J Med Sci 1977;146:162-6.

45. Watier A, Devroede G, Duranceau A, et al. Constipation with colonic inertia. A manifestation of systemic disease? Dig Dis Sci 1983;28:1025-33.

46. Whorwell PJ, Lupton EW, Erduran D, Wilson K. Bladder smooth muscle dysfunction in patients with irritable bowel syndrome. Gut 1986;27:1014-7.

47. Whorwell PJ, McCallum M, Creed FH, Roberts CT. Non-colonic features of irritable bowel syndrome. Gut 1986; 27:37-40

48. Fielding JF, Regan R. Excessive cold pressor response in the irritable colon syndrome. Ir J Med Sci 1984; 153:348-50.

49. Chen S, Winke J, Zhang Q. Abnormal blood pressure: An important nongastrointestinal manifestation in patients with the irritable bowel syndrome. Proc R Coll Phys Surg (Edin) 1989;19;39-42.

50. Cockcroft DW, Killian DN, Mellon JJA, Hargreave FE. Bronchial reactivity of inhaled histamine: A method and clinical survey. Clin Allergy 1977; 7:235-43.

51. Hargreave FE, Ryan G, Thomson NC, et al. Bronchial responsiveness to histamine or methacholine in asthma: Measurement and clinical significance. J Allergy Clin Immunol 1981; 68:347-55.

52. Juniper EF, Frith PA, Dunnett C, Cockcroft DW, Hargreave FE. Reproducibility and comparison of responses to inhaled histamine and methacholine. Thorax 1978; 33:705-10.

53. Hargreave FE, Dolovich J, O'Byrne PM, Ramsdale EH, Daniel EE. The origin of airway hyperresponsiveness. J Allergy Clin Immunol 1986;78:825-32.

54. White A, Upton A, Collins SM. Is irritable bowel syndrome the asthma of the gut? Gastroenterology 1988; 94:A494.

55. Reed JW. Emotional factors in bronchial asthma. Psychosomatics 1962;3:57-66.

56. Rees WL. Etiological factors in asthma. Psychiatr J Univ Ottawa 1980:5:51-4.

57. Graham P, Rutter M, Yule W, Pless I. Childhood asthma: A psychosomatic disorder? Clinical and epidemiological considerations. Br J Preven Soc Med 1967;21;78-85.

58. Cockcroft DW. Mechanism of perennial allergic asthma. Lancet 1983;ii:253-6.

59. Chaudhary NA, Truelove SC. The irritable bowel syndrome. QJ Med 1962;123:307-22.

60. Holgate ST, Hardy C, Robinson C, Agius RM, Howarth PH. The mast cell as a primary effector cell in the pathogenesis of asthma. J Allergy Clin Immunol 1986;77:274-82.

61. Hiatt RB, Katz L. Mast cells in inflammatory conditions of the gastrointestinal tract. Am J Gastroenterol 1962;37:541-5. 


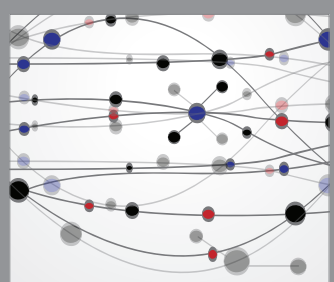

The Scientific World Journal
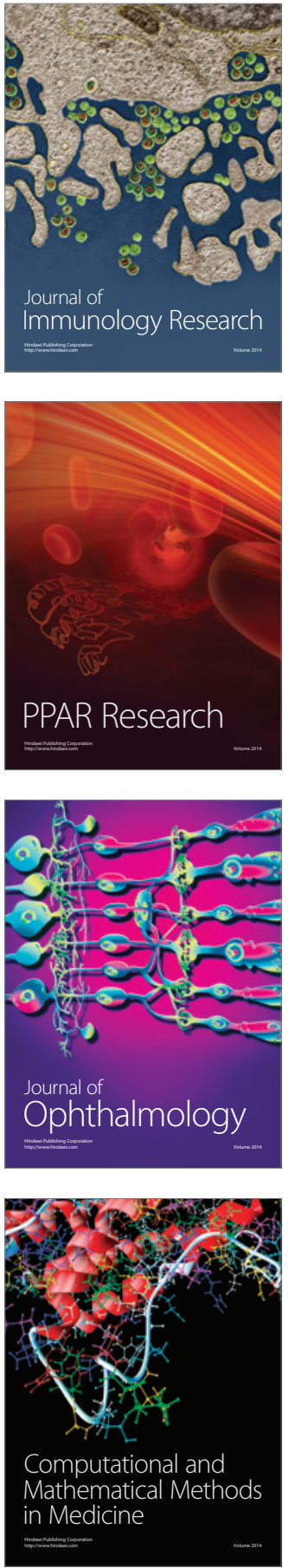

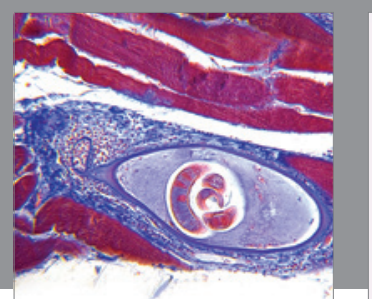

Gastroenterology Research and Practice

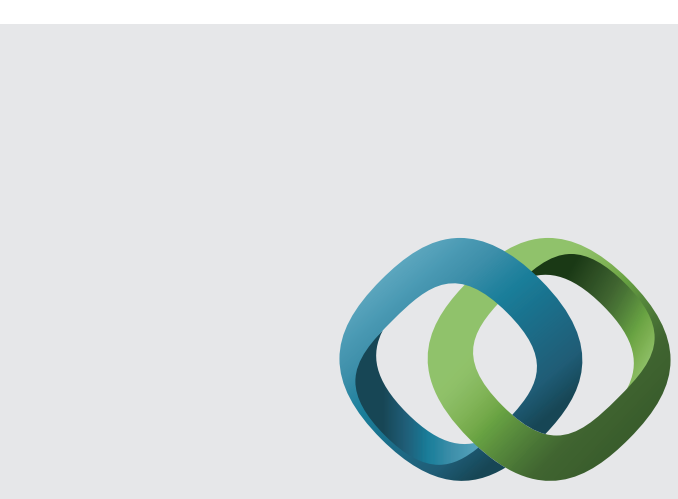

\section{Hindawi}

Submit your manuscripts at

http://www.hindawi.com
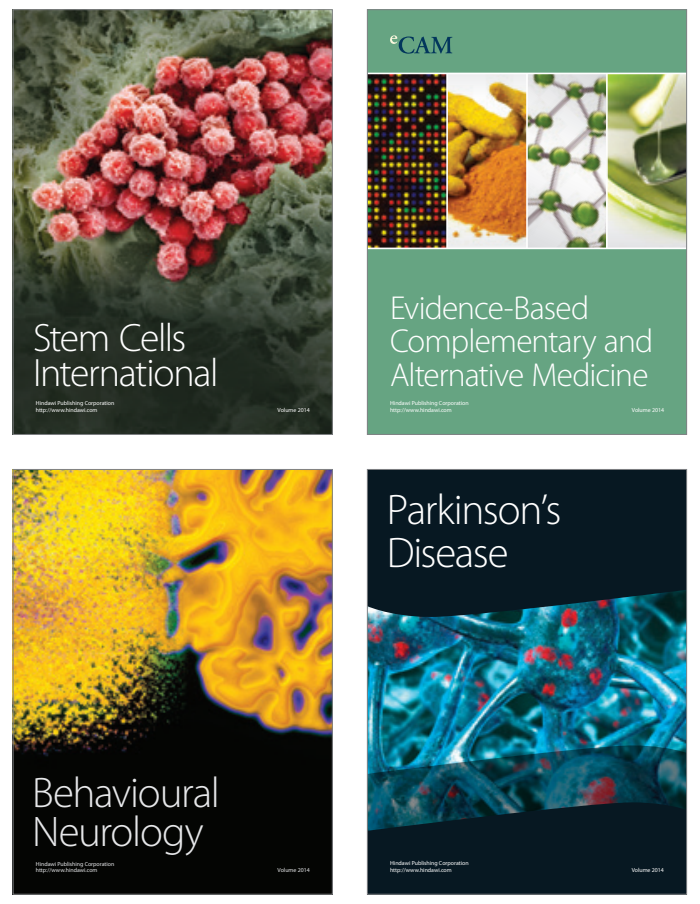
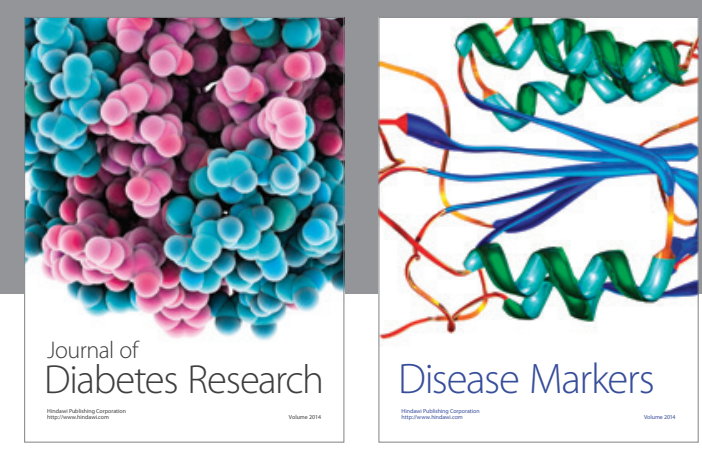

Disease Markers
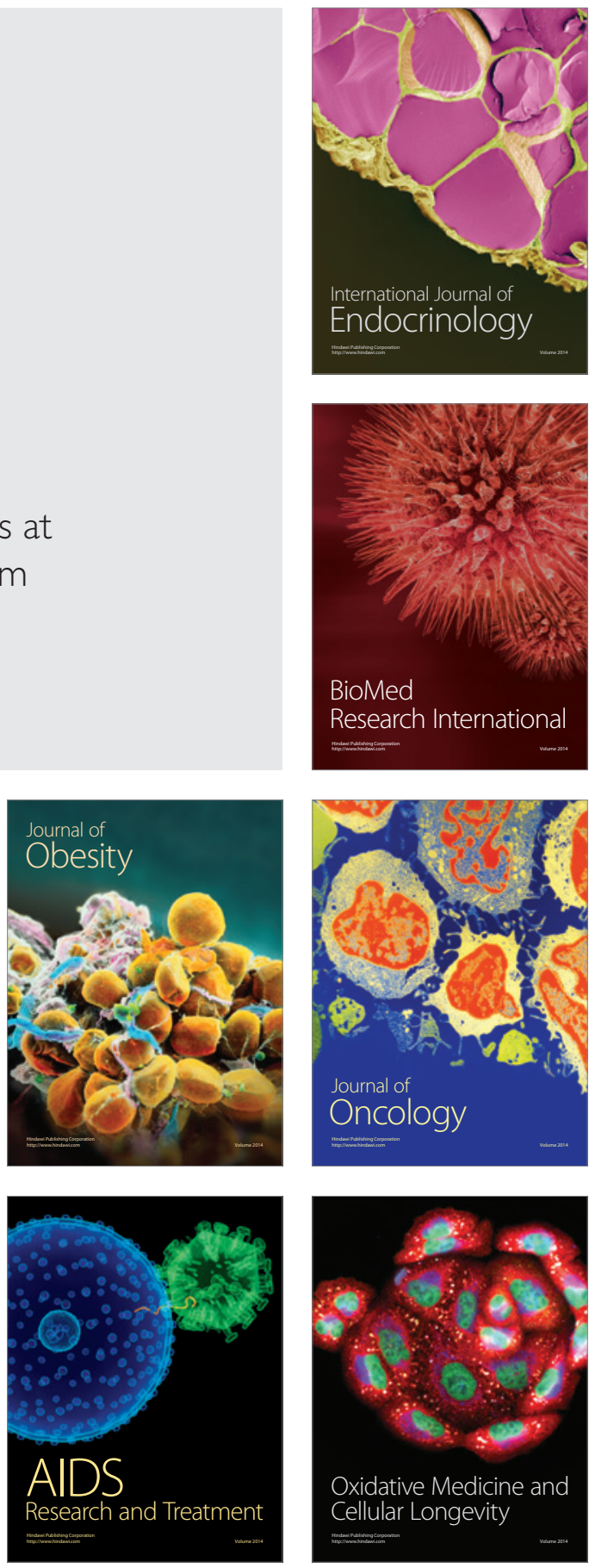